\title{
Determining suitable dimensions for dairy goat feeding places by evaluating body posture and feeding reach
}

\author{
Nina M. Keil, ${ }^{* 1}$ Marc Pommereau, ${ }^{*}$ Antonia Patt, $†$ Beat Wechsler, ${ }^{*}$ and Lorenz Gygax* \\ *Swiss Federal Veterinary Office, Centre for Proper Housing of Ruminants and Pigs, Agroscope Tänikon, CH-8355 Ettenhausen, Switzerland \\ †Department of Animal and Avian Sciences, University of Maryland, College Park 20742
}

\begin{abstract}
Confined goats spend a substantial part of the day feeding. A poorly designed feeding place increases the risk of feeding in nonphysiological body postures, and even injury. Scientifically validated information on suitable dimensions of feeding places for loose-housed goats is almost absent from the literature. The aim of the present study was, therefore, to determine feeding place dimensions that would allow goats to feed in a species-appropriate, relaxed body posture. A total of 27 goats with a height at the withers of 62 to $80 \mathrm{~cm}$ were included in the study. Goats were tested individually in an experimental feeding stall that allowed the height difference between the feed table, the standing area of the forelegs, and a feeding area step (difference in height between forelegs and hind legs) to be varied. The goats accessed the feed table via a palisade feeding barrier. The feed table was equipped with recesses at varying distances to the feeding barrier $(5-55 \mathrm{~cm}$ in 5 -cm steps) at angles of $30^{\circ}, 60^{\circ}, 90^{\circ}, 120^{\circ}$, or $150^{\circ}$ (feeding angle), which were filled with the goats' preferred food. In 18 trials, balanced for order across animals, each animal underwent all possible combinations of feeding area step (3 levels: 0, 10, and $20 \mathrm{~cm}$ ) and of difference in height between feed table and standing area of forelegs (6 levels: $0,5,10,15,20$, and $25 \mathrm{~cm}$ ). The minimum and maximum reach at which the animals could reach feed on the table with a relaxed body posture was determined for each combination. Statistical analysis was performed using mixed-effects models. The animals were able to feed with a relaxed posture when the feed table was at least $10 \mathrm{~cm}$ higher than the standing height of the goats' forelegs. Larger goats achieved smaller minimum reaches and minimum reach increased if the goats' head and neck were angled. Maximum reach increased with increasing height at withers and height of the feed table. The presence of a feeding
\end{abstract}

Received February 2, 2016.

Accepted October 7, 2016.

${ }^{1}$ Corresponding author: nina.keil@agroscope.admin.ch area step had no influence on minimum and maximum reach. Based on these results, the goats' feeding place can be designed to ensure that the animals are able to reach all of the feed in the manger or on the feed table with a relaxed posture, thus avoiding injuries and nonphysiological stress on joints and hooves. A feeding area step up to a maximum of $20 \mathrm{~cm}$ need not be taken into account in terms of feeding reach. However, the feed table must be raised at least $10 \mathrm{~cm}$ above the standing area to allow the goats to feed in a species-appropriate, relaxed posture.

Key words: goat, feeding behavior, body posture, dimensions of feeding place

\section{INTRODUCTION}

Goats feed for a substantial part of the day, consuming several meals over 2 main periods (early and late in the daytime). Depending on the diet, daily feeding time is 6 to $9 \mathrm{~h} / \mathrm{d}$ in confined housing (Abijaoudé et al., 2000 ) and 7 to $10 \mathrm{~h} / \mathrm{d}$ on pasture (Ferreira et al., 2013). Agonistic interactions in the feeding area are common among goats; because of their browsing feeding behavior they forage selectively, and higher-ranking goats chase lower-ranking herd members away from preferred food (Barroso et al., 2000). In intensive housing conditions, these interactions can be mediated by the feed (e.g., quality, amount, distribution) and spatial conditions (e.g., number and size of feeding places, size of lying area) available in the pen (Barroso et al., 2000; Loretz et al., 2004; Andersen and Boe, 2007; Aschwanden et al., 2008). However, encounters also lead to frequent changes of feeding place, and hence to repeated entry into and exit from the feeding barrier. Given the hours spent feeding each day, this means that the animals are in frequent contact with the feeding barrier, which poses a risk of injury if poorly designed (Kielland et al., 2010).

In dairy goat housing, several types of feeding barriers are used. Neck rails are continuous horizontal rails or boards that lack physical separation between single feeding places, resulting in frequent displacements 
(Nordmann et al., 2013). With diagonal feed fences or self-locking feeding barriers, goats are physically separated by vertical bars but must twist their heads to pass them through the openings; therefore, duration for leaving this type of barrier is increased (Nordmann et al., 2013). By contrast, the more goat-friendly palisade or tombstone feeding barriers - characterized by upright (wooden or metal) posts spaced at intervals that allow insertion of the neck but not the head from above - reduce the risk of being hindered by the bars of the opening. Animals can easily enter or exit these barriers simply by lifting or lowering their heads, respectively. This is particularly important when a lowerranking animal needs to free its head from the feeding barrier to give way to a higher-ranking herd member (Nordmann et al., 2013).

At the same time, however, for the sake of speciesappropriate feeding and goat welfare, it is essential that the feeding place be correctly sized so as to avoid bruising or hematomas from the feeding barrier, and to not restrict the animals' freedom of movement during feeding or social interactions. It is only when goats can feed in a relaxed posture without having to brace themselves against the feeding barrier to reach the feed that the pressure of the feed barrier on the animals' bodies is minimized (Dumelow, 1987) and skin lesions and nonphysiological stress on joints and hooves are prevented.

The literature recommends an animal-to-feeding place ratio of at least 1:1 (Loretz et al., 2004; Jørgensen et al., 2007) and feeding place widths of 35 to $40 \mathrm{~cm}$ per goat (Toussaint, 1997; Loretz et al., 2004). However, other dimensions known to be relevant in cattle, such as the height of the feeding barrier (e.g., neck rail), the height of the partition between pen and feed table, the depth of a feed table or manger, and the height of a feed table (Fernández et al., 2006; Huzzey et al., 2006; Kielland et al., 2010), have not been scientifically investigated to any great extent in goats (Muhikambele et al., 1998).

Adequate dimensions for a feed barrier must be based on the animals' body measurements (Fernández et al., 2006). In goats, height at withers is an appropriate predictor, as it is easy to measure as well as highly correlated with other body dimensions and weight (Muhikambele et al., 1998). For the height of the feeding barrier, for example, it is reasonable to assume that a neck rail must be at least slightly higher than the animals' height at withers (Kielland et al., 2010). For feed table height and depth, determining adequate dimensions is not as simple, as they are mutually dependent. The depth of a feed table or manger determines the maximum distance at which feed is made available to the animals. Hence, the depth of the feed table is adequate when the animals can reach and consume all of the feed across the entire width of the feeding place with a relaxed posture. It can be assumed that larger animals have a greater reach and can thus reach the feed more easily than smaller animals, and that reach decreases toward each side of the feeding place when the goats need to twist their necks. It can also be assumed that increasing the height of the feed table increases the reach of the animals. Here, work economics considerations also highlight the importance of finding a suitable combination of feed table height and depth, as these 2 dimensions, together with the height of the partition between pen and feed table, determine loading capacity (the maximum feed volume that can be dispensed at any one time).

With regard to reach, depending on the system, feeding places for goats do not always have solid flooring, but pens are often bedded with straw up to the feeding barrier. In barns of this type, the growing layer of manure constantly reduces the height of the feeding barrier. For this reason, the dimensions of the feed barrier generally take account of the maximum height of the manure layer. Particularly after dung removal, the feeding barrier is unsuitably high, which is why a feeding area step is often provided. The animals can stand with their forelegs on the step to lift their bodies, thereby overcoming the height difference, but the ensuing change in posture (in which the forelegs are higher than the hind legs, and the line of the back is bent) could limit the goats' reach at the feed table.

The aim of our study was, therefore, to investigate the reach of feeding goats in relation to their height at withers by varying the height of the feed table (difference in level between the standing area of the forelegs and the feed table) and of a feeding area step (difference in level between fore and hind legs). Using a similar approach here to Muhikambele et al. (1998), who specified the maximum vertical and horizontal reach of goats, we determined the feeding reach for feed table dimensions of practical relevance and included the goats' posture during feeding to ensure species-appropriate feeding.

\section{MATERIALS AND METHODS}

\section{Experimental Animals}

Ethical approval to conduct the study was obtained from the Cantonal Veterinary Office, Thurgau, Switzerland (Approval No. F4/09). A total of 27 adult, lactating, healthy dairy goats in average body condition on 2 dairy goat farms with loose housing and a barrier feeding system were chosen for the data collection process. Breeds represented were Appenzeller (14 animals), Grisons Striped (3 animals), Chamois Colored (6 animals), 
and Saanen (4 animals). Owing to the construction of the experimental feeding stall, only hornless or polled animals were selected, as the horns of some of the animals were too large to ensure unimpeded access to the feed table. In Switzerland, Appenzeller and Saanen goats are usually bred hornless, and kids with horns are dehorned; whether or not Grison Striped and Chamois Colored are dehorned depends on the breeding aim of the farmer.

To cover as wide a size range of animals as possible, the smaller Appenzeller goats and the larger specimens of the other, bigger breeds were chosen in each herd on the basis of visual inspection. The height at withers of the experimental goats ranged between 62 and $80 \mathrm{~cm}$.

\section{Design of the Feeding Stall}

For the study, an experimental feeding stall was constructed that allowed us to vary the height of the feeding area step and feed table. It also enabled us to determine the animals' reach and record their posture during feeding. With internal dimensions of $44 \mathrm{~cm}$ wide by $100 \mathrm{~cm}$ long and high, the feeding stall was designed to accommodate a single goat at any one time. The sides of the stall were closed off with wire mesh to allow observation of the experimental animal during feeding (Figures 1 and 2). A palisade feeding barrier and a neck rail were designed that could be individually adapted to the animal's size (Figure 1).

To investigate the influence of the feeding area step, we altered the standing level of the forelegs with respect to that of the hind legs. For this, a wooden chest with a footprint of $40 \times 20 \mathrm{~cm}$ and with 2 different height settings was placed in front of the feeding barrier (3 levels: 0,10 , and $20 \mathrm{~cm}$ ). A board that could be fitted at different heights compared with the standing level of the forelegs (6 levels: 0, 5, 10, 15, 20, and 25 $\mathrm{cm})$ served as a feed table and was mounted in front of the feeding barrier. The board had 28 recesses with a diameter of $3.5 \mathrm{~cm}$ and a depth of $0.5 \mathrm{~cm}$ in which feed was provided. The recesses were arranged radially around the center of the feeding place at distances of 5 to $55 \mathrm{~cm}$ to the center and $5 \mathrm{~cm}$ apart. This allowed us to evaluate the minimum and maximum reach of the goats as a function of the angle of the head to the feeding barrier. Alternate use was made of 2 different feed tables. One feed table had recesses at $30^{\circ}, 90^{\circ}$, and $120^{\circ}$ angles, whereas the second one had them at $60^{\circ}$, $90^{\circ}$, and $150^{\circ}$ angles (Figure 3 ). As it was assumed that corresponding angles $\left(30^{\circ} / 150^{\circ}\right.$ and $\left.60^{\circ} / 120^{\circ}\right)$ would allow for the same reach, half of the animals were tested with the $30^{\circ}-90^{\circ}-120^{\circ}$ board and the other half with the $60^{\circ}-90^{\circ}-150^{\circ}$ board. A given goat was thus tested with a lowered number of possible angles. This approach

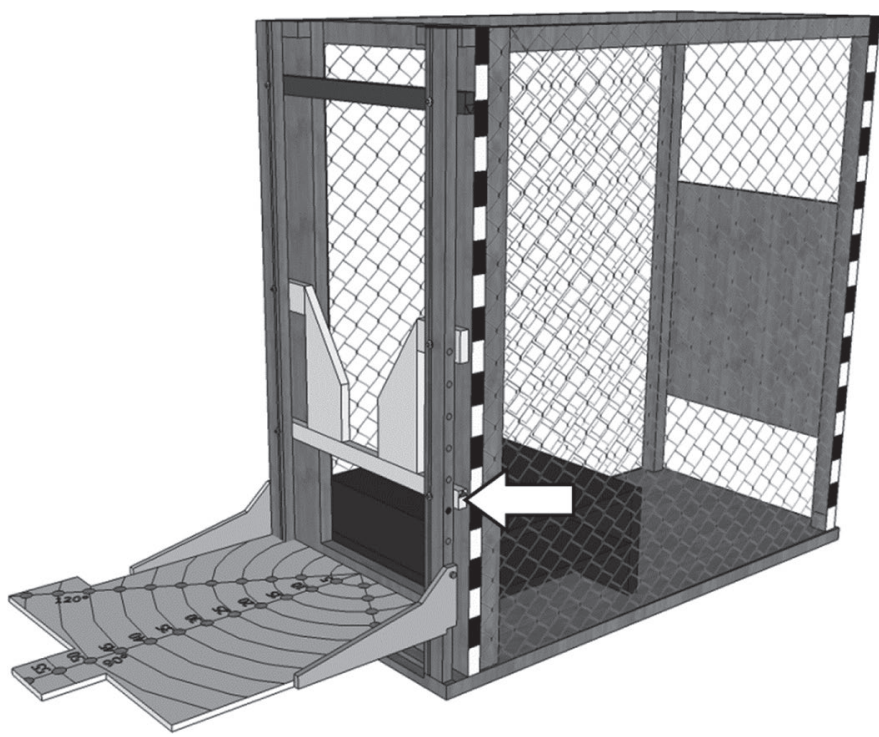

Figure 1. Sketch of the feeding stall with 1 of the 2 feed table variants (Figure 3), with height of feed table in relation to forelegs being adjustable from 0 to $25 \mathrm{~cm}$ in 5 -cm steps. The height difference between forelegs and hind legs was achieved by placing a wooden chest under the forelegs ( 0 to $20 \mathrm{~cm}$ in $10-\mathrm{cm}$ steps). Goats accessed the feed table via a palisade feeding barrier, and a neckrail at least $30 \mathrm{~cm}$ above their withers prevented their exit from the feeding stall. The height of the partition separating the standing area of the forelegs and the feed table (see arrow) was individually adjusted to the height of the point of the shoulder.

reduced the time goats spent taking part in the experiment (i.e., prevented them from consuming too much feed and from being separated from their conspecifics for long periods).

\section{Experimental Procedure}

Goats were tested one at a time using the 18 possible combinations of foreleg height to hindleg height and feed table height to foreleg height (Figure 2). For each tested goat, the height of the partition between the standing area of the forelegs and the feed table was adjusted to below the base of the neck and levelled with the point of the shoulder to values of 35 to $55 \mathrm{~cm}$. This ensured that the base of the neck of the feeding animal did not rest on the edge of the partition. The neck rail was set as deep as possible for the individual goat, but at least $30 \mathrm{~cm}$ above withers height to prevent the goat from being able to leave the stall via the feeding barrier. Therefore, the animal had unrestricted freedom of movement as it fed.

A food lure was placed in the 28 recesses of the feed table. It consisted of the farm's own grist, dried apple pomace, or sliced carrots. Goats were familiar with these food types and each goat was offered her preferred food type based on preference tests made before the start of 


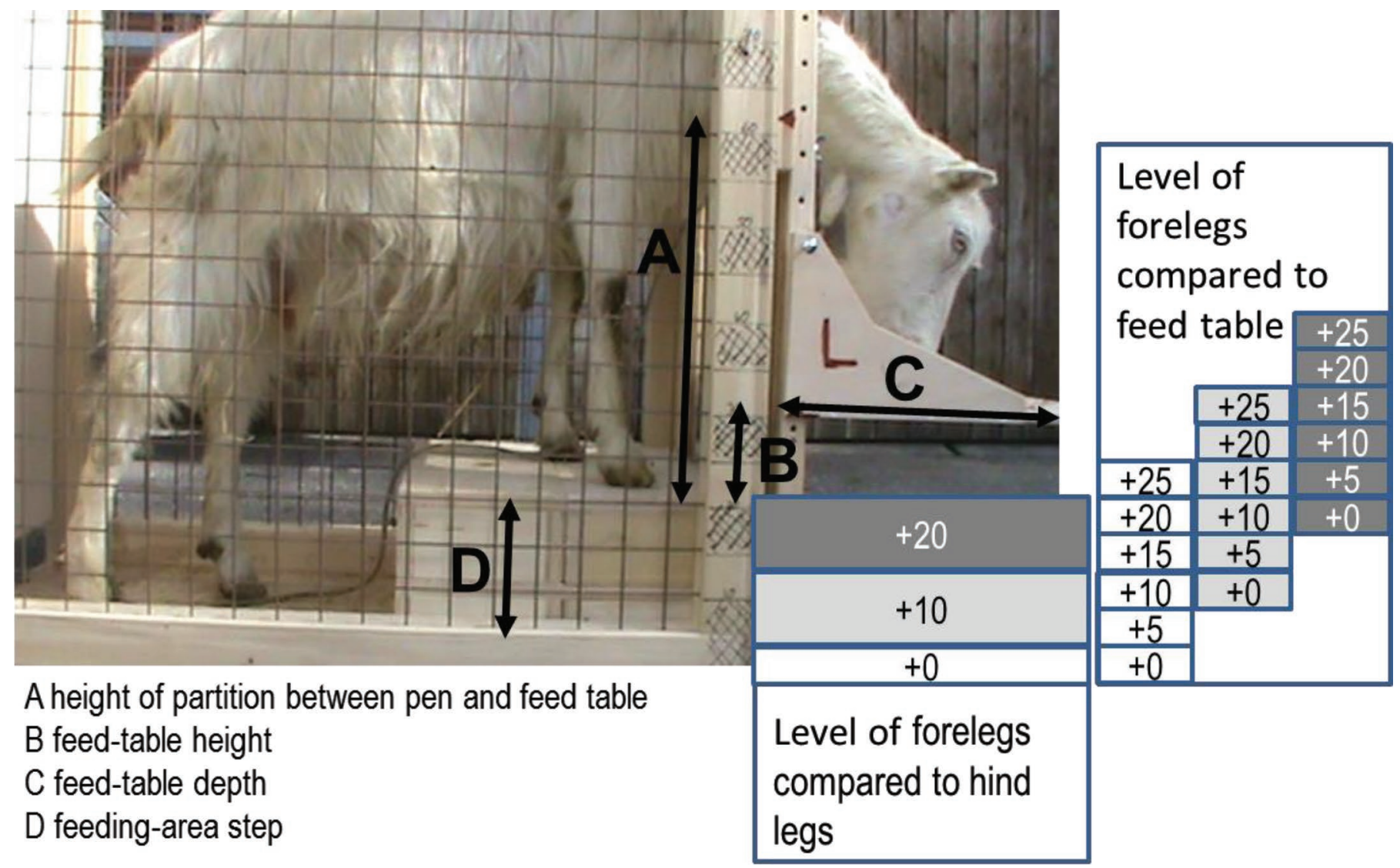

Figure 2. Photo of the feeding stall showing the 18 combinations of 3 levels of standing height of forelegs in relation to hind legs, and 6 levels of feed table height in relation to standing height of forelegs (in cm). Arrows define height of partition between pen and feed table (A), feed-table height (B), feed-table depth (C), and feeding-area step (D). The photo shows an example with the standing height of the forelegs $20 \mathrm{~cm}$ above the hind legs and feed table height $10 \mathrm{~cm}$ above the standing height of the forelegs. Color version available online.

the experiment. Just a few crumbs or small pieces of the food lure were placed in each recess. The amount was sufficient for assessing the goats' posture when feeding from any chosen recess, but small enough to guard against satiety and a resulting lack of appetite in the experimental animals. This also prevented digestive irritation caused by excess concentrate consumption.

Each animal went through all possible combinations in a total of 18 trials. To minimize the time each goat would need to spend in the feeding stall and to keep the animals motivated to participate in the trials, we optimized the time for changing the experimental conditions. For this, each animal was tested in the feeding stall with the 3 different feeding area step heights (phase). In each of these 3 phases, the 6 different feed table heights were provided (variant). To control for a habituation effect in the animals, the sequences of the settings of continuously increasing and decreasing height were systematically varied and offered to the animals in a balanced manner. From phase to phase, step heights either increased $(0,10$, or $20 \mathrm{~cm})$ or de- creased $(20,10$, or $0 \mathrm{~cm})$. Within a phase, feed table heights also either increased $(0-25 \mathrm{~cm}$ in 5 -cm steps) or decreased $(25-0 \mathrm{~cm}$ in 5 -cm steps). For the 3 phases of 1 animal, there was an alternating increase or decrease in feed table height from one phase to another; that is, an animal either had increasing feed table height in phase 1 , decreasing height in phase 2 and increasing height in phase 3 , or else started with increasing table height in phase 1 followed by decreasing height in phase 2 and increasing height in phase 3 . This resulted in 4 different sequences; combined with the 2 types of feeding tables $\left(30^{\circ}-90^{\circ}-120^{\circ}\right.$ and $60^{\circ}-90^{\circ}-150^{\circ}$ board), this produced 8 different arrangements, each of which were presented to 3 to 4 animals.

A video camera was positioned to the side of the feeding stall to record the posture of the test animal as it fed. The animal's posture was defined as relaxed when it fed standing evenly on all 4 legs without bracing itself against the feeding barrier. The animal was recorded as having a nonrelaxed body posture as soon as it was only able to reach the feed in a recess by 
stretching or extending its neck, head, or tongue, pressing its body into the feeding barrier, resting its neck on the edge of the manger, or bending at the carpal joints. In all of these instances, the body's center of gravity was shifted forward and the withers were lowered. This could be observed as changes in shoulder position with respect to the forelegs, and changes in the relative difference in height beween withers and hips.

An audio track was recorded simultaneously with the video camera. The investigator (M. Pommereau) stood several meters away from the feeding stall to minimize any influence of his presence and observed the animal at the feed table. He then verbally stated the recess at which an animal fed at a particular point in time. This allowed us to associate the animal's posture with its feeding reach and direction at the time. The experimental setting was changed as soon as the animal's maximum reach had been achieved at least 2 times and it had shown that reaching beyond this point would only be possible by adopting a nonrelaxed body posture. To gauge the size of the animals, the height at withers of the goats was determined on the basis of the video recordings using marks on the feeding stall (i.e., without the influence of a person taking measurements or contact with a measuring instrument). The feeding stall (internal dimension $=44 \mathrm{~cm}$ ) was not much wider than the goats themselves, which prevented the animals from turning substantially sideways, allowing us to minimize a bias in measurements for reach and height at withers.

For the analysis, the maximum and minimum reach achieved by the animals with a relaxed body posture was determined for each of the feeding angles (i.e., angles of the feed table) studied. The maximum reach was the recess furthest from the feeding barrier whose contents were completely consumed by the goats. The minimum reach was the feed table recess from which the goats fed that was closest to the feeding barrier. Based on a preliminary analysis showing no differences in reach, the angles of $30^{\circ}$ and $150^{\circ}$ on the one hand and $60^{\circ}$ and $120^{\circ}$ on the other were combined. To assess intraobserver agreement, the investigator (M. Pommereau) re-evaluated the videos of 3 random chosen goats in October 2016 (4 yr after the original coding); this resulted in 126 values for maximum reach (i.e., in a relaxed posture). When compared with the original data, the maximum reach was assessed with a concordance correlation coefficient of 0.988 (95\% CI = 0.984-1.000; function agreement in $\mathrm{R}$ package Agreement, Yu and Lin, 2012).

\section{Statistical Analysis}

Linear mixed-effects models in $\mathrm{R}$ (version 3.2.0; $\mathrm{R}$ Core Team, 2015) with functions from the MuMIn (Barton, 2012) and nlme (Pinheiro et al., 2012) packages

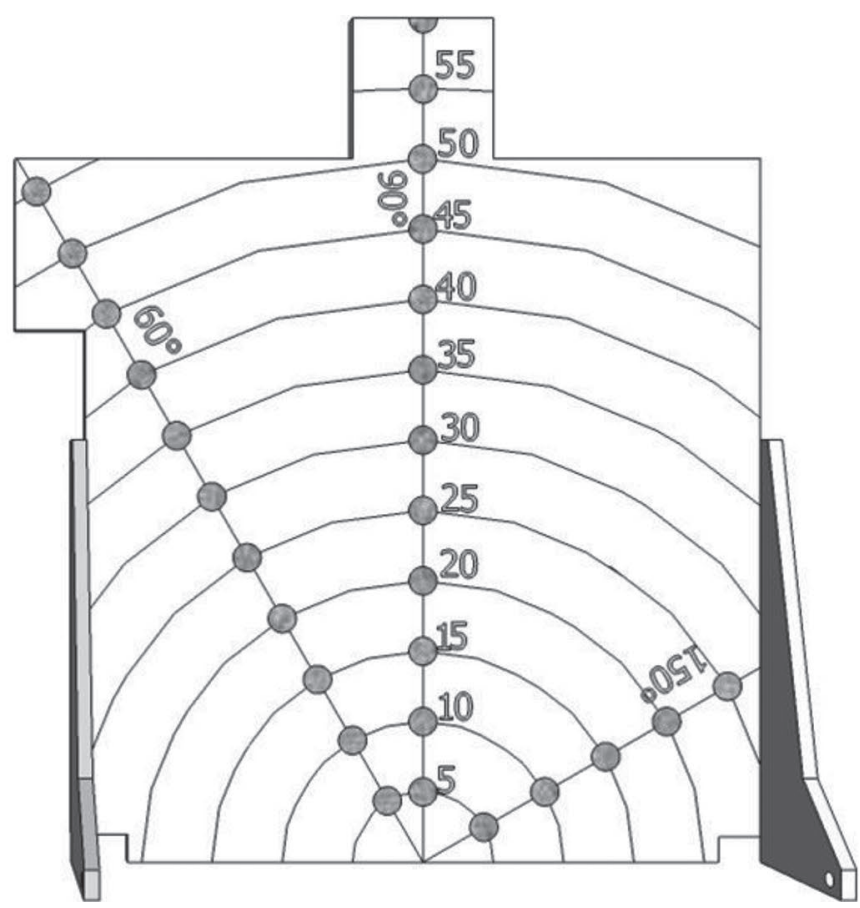

Figure 3. Sketch of the 2 feed tables with recesses for feed at various angles $\left(30^{\circ} / 120^{\circ}, 60^{\circ} / 150^{\circ}\right.$, and $\left.90^{\circ}\right)$ and distances (in $\mathrm{cm}$, ranging from 5 to $55 \mathrm{~cm}$ in 5 -cm steps) for assessing feeding reach (top view). 
were used for the statistical analysis. The assumptions of the models were checked for normal distribution and variance homogeneity using a graphical residual analysis. The maximum and minimum reach were examined as outcome variables.

As the feeding boards had the same external width as the feeding stall $(50 \mathrm{~cm})$, the maximum possible reach for the $30^{\circ}$ and $150^{\circ}$ angles of the feed boards was limited to $25 \mathrm{~cm}$. Most goats achieved this reach for all standing and feed table heights. Consequently, the data for these 2 angles were excluded from the statistical analysis. Furthermore, most of the goats were unable to feed with a relaxed posture when the difference between standing height of the forelegs and feed table height was 0 or $5 \mathrm{~cm}$ (see Results), with the result that these feed table heights were also excluded from the analysis.

The fixed effects feeding area step (factor with 3 levels: 0, 10, and $20 \mathrm{~cm}$ ) and feed table height (i.e., the difference in height between the feed table and the standing height of the forelegs; factor with 4 levels: $10,15,20$, and $25 \mathrm{~cm}$ ) as well as the animal's height at withers and feeding angle (both continuous) served as explanatory variables. As the 6 different feed table heights (variants) were tested for each animal within the 3 different heights of the feeding area step (phases), the random effect was variant nested in phase nested in animal.

For each outcome variable, an all-subset analysis was carried out ranging from the smallest model containing only the intercept to the largest possible model with all explanatory variables, including their interactions. The best model was chosen with the aid of the Bayesian information criterion, based on which the probability $\left(\mathbf{w}_{\mathbf{i}}\right)$ of each model in the set being the best model given the data was calculated. Based on $\mathrm{w}_{\mathrm{i}}$ we also calculated the evidence ratio $\left(\mathbf{E}_{0}\right)$, which indicates how many times more likely the chosen model is than the null model (which contains only the intercept).

\section{RESULTS}

Feeding was observed at the feed table for $75 \%$ ( $\mathrm{n}=$ 1,096 ) of all 1,458 possible data points (27 animals $\times 18$ trials $\times 3$ angles). Missing values were the result of the animals' complete refusal to feed in a given trial (all 3 angles missing; 8 animals in a total of 57 trials, 1 to 14 trials per animal) or not consuming feed from all angles in a trial ( 1 angle missing in 135 trials, 2 angles missing in 28 trials) and were omitted from the analysis. The percentage of data points where feeding with a relaxed posture could be seen and data points with feeding at the feed table $(\mathrm{n}=1,096)$ was $11 \%$ for a feed table height of $0 \mathrm{~cm}, 46 \%$ for a feed table height of $5 \mathrm{~cm}$, and $94 \%$ for a feed table height of $10 \mathrm{~cm}$. From a feed table height of $15 \mathrm{~cm}$ above standing level upwards, this percentage was $100 \%$; this applied equally for the minimum and maximum reach.

For the minimum reach, the best possible model contained feeding angle and height at withers as explanatory variables (Table 1). Feed table height and feeding area step, however, had no detectable influence on minimum reach. The minimum reach for the $90^{\circ}$ angle was approximately $3 \mathrm{~cm}$ less than for the $60^{\circ} / 120^{\circ}$ angles (Figure 4A). Larger goats achieved smaller minimum reaches, with the difference between goats with a height at withers of 80 and $60 \mathrm{~cm}$ being approximately $8 \mathrm{~cm}$. According to the data distribution (minimum, maximum, and 1st and 3rd percentiles), variability was very high from goat to goat between the trials and, as the median shows, the goats achieved a minimum reach of less than approximately $15 \mathrm{~cm}$ in only half of the trials. The next-most-probable model contained the feeding angle as the sole explanatory variable $\left(\mathrm{w}_{\mathrm{i}}=\right.$ $0.338, \mathrm{E}_{0}>676$ ); all further models had markedly lower probabilities.

In terms of the maximum reach, the best possible model contained height at withers and feed table height as explanatory variables. Feeding angle and feeding area step, however, had no detectable influence on maximum reach, which increased along with the height of the feed table (Figure 4B). Here, the increase in reach was not proportional to the increase in feed table height; whereas the maximum reach for animals with a height at withers of $70 \mathrm{~cm}$ was approximately $29 \mathrm{~cm}$ at a feed table height of $10 \mathrm{~cm}$, maximum reach was approximately $41 \mathrm{~cm}$ for a feed table height of $25 \mathrm{~cm}$.

Table 1. Result of the chosen model for minimum and maximum reach according to Bayesian information criterion: explanatory variables and estimated effects

\begin{tabular}{lll}
\hline Outcome variable & Explanatory variables & Estimated effect \\
\hline Minimum reach $(\mathrm{cm})$ & Feeding angle $\left(^{\circ}\right)$, & $-0.099 \mathrm{~cm} \mathrm{reach} /{ }^{\circ}$, \\
$\left(\mathrm{w}_{\mathrm{i}}=0.439, \mathrm{E}_{0}>878\right)^{1,2}$ & height at withers $(\mathrm{cm})$ & $-0.408 \mathrm{~cm} \mathrm{reach} / \mathrm{cm}$ \\
Maximum reach $(\mathrm{cm})$ & Feed table height $(\mathrm{cm})$, & $+0.773 \mathrm{~cm} \mathrm{reach} / \mathrm{cm}$, \\
$\left(\mathrm{w}_{\mathrm{i}}=0.459, \mathrm{E}_{0}>918\right)^{1,2}$ & height at withers $(\mathrm{cm})$ & $+0.248 \mathrm{~cm} \mathrm{reach} / \mathrm{cm}$ \\
${ }^{1} \mathrm{w}_{\mathrm{i}}=$ Bayes weight, which can be interpreted as the probability of the model within the set. \\
${ }^{2} \mathrm{ER}_{0}=$ evidence ratio between the chosen model and the null model (including only the intercept).
\end{tabular}



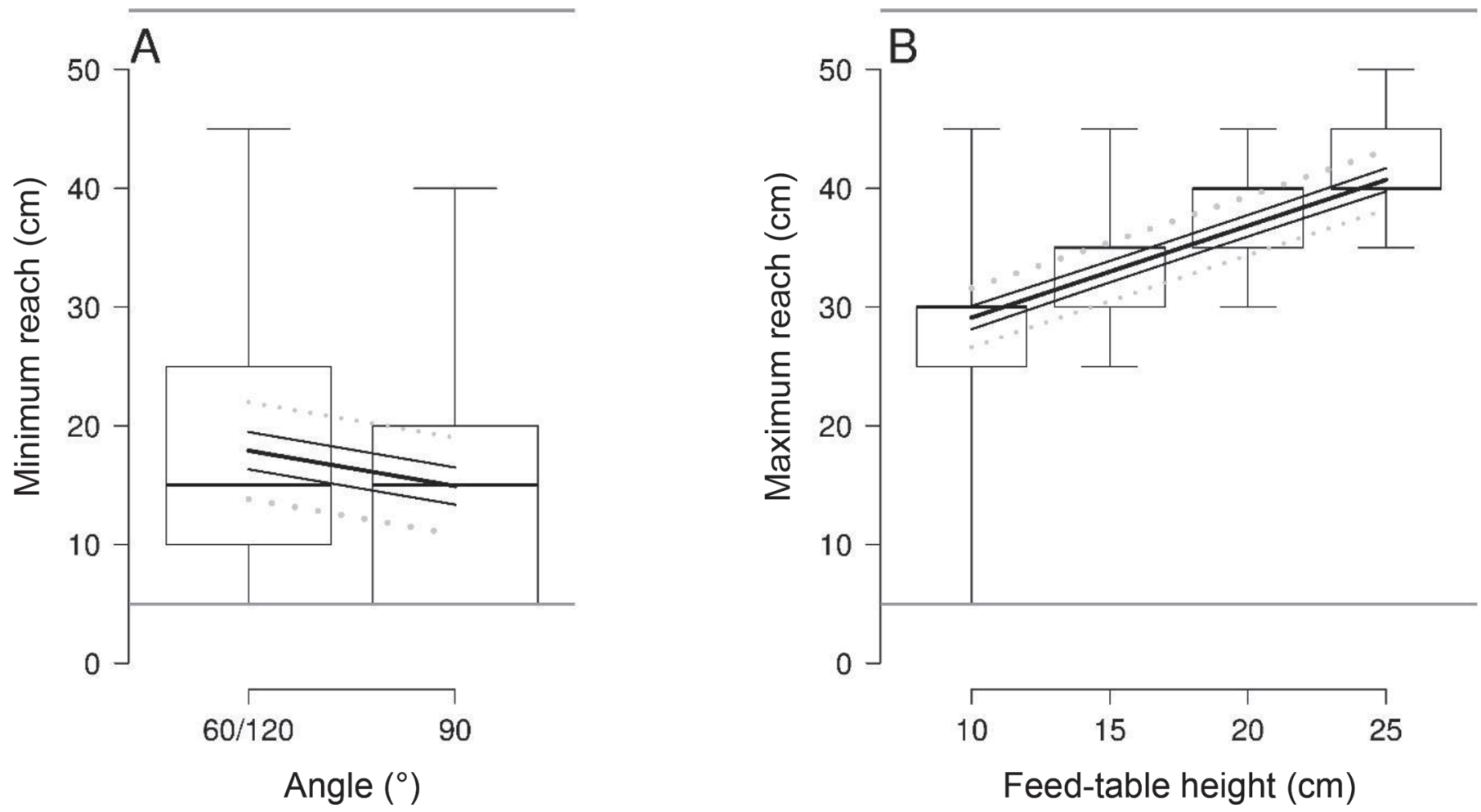

Figure 4. Goats' feeding reach: minimum feeding reach $(\mathrm{A})$ in relation to height at withers and feeding angle and maximum feeding reach (B) in relation to height at withers and feed table height (difference in relation to standing area of forelegs). Original data in box and whisker plots $($ boxes $=1$ st and 3 rd quartile, thick line $=$ median, whiskers $=$ reach from minimum to maximum value). Solid black lines show model estimates for height at withers $=70 \mathrm{~cm}$ (bold) with $95 \%$ CI (thin); gray dotted lines show model estimates for height at withers $=80 \mathrm{~cm}$ (bold) and height at withers $=60 \mathrm{~cm}$ (thin); gray solid lines show minimum and maximum potential reach.

According to the model estimate, animals with a height at withers of 60 and $80 \mathrm{~cm}$ differed by approximately $5 \mathrm{~cm}$ in their maximum reach. The next-most-probable model contained feed table height $\left(\mathrm{w}_{\mathrm{i}}=0.387, \mathrm{E}_{0}>774\right)$ as the sole explanatory variable. All further models had markedly lower probabilities.

Based on these results, we calculated the maximum possible depth of a feed table or manger as a function of the height of the feed table or bottom of the manger for

Table 2. Practical recommendations for maximum feed table or manger depth (in $\mathrm{cm}$ ) allowing goats to reach all of the feed spread over the entire width of a feeding place $(35-40 \mathrm{~cm}$ wide) with a relaxed posture, as a function of the animal's height at withers and feed table or manger height ${ }^{1}$

\begin{tabular}{lcccc}
\hline & \multicolumn{4}{c}{ Height of feed table or manger $(\mathrm{cm})$} \\
\cline { 2 - 5 } $\begin{array}{l}\text { Height at } \\
\text { withers }(\mathrm{cm})\end{array}$ & 10 & 15 & 20 & 25 \\
\hline 60 & 20 & 25 & 30 & 35 \\
70 & 23 & 28 & 33 & 37 \\
80 & 25 & 30 & 35 & 40 \\
\hline
\end{tabular}

${ }^{1}$ For example, given a feed table height of $10 \mathrm{~cm}$ and a goat with a height of $60 \mathrm{~cm}$ at withers, feed table depth should not exceed $20 \mathrm{~cm}$.
3 different sizes of goats given a feeding place width of 35 and $40 \mathrm{~cm}$ per animal, both of which are common in practice. These calculations can serve as a recommendation for use in practice, ensuring that the animals can reach all the feed from the center of the feeding place outwards with a relaxed body posture (Table 2). Here, we assumed that the animals maintained the reach they had at $90^{\circ}$ and $60^{\circ} / 120^{\circ}$ in the same radius (Figure 5). The recommended depths are therefore smaller than the maximum reach at $90^{\circ}$, so feed lying to the side can also be reached comfortably by the goat at the depth provided by the feeding place and no blind areas arise.

\section{DISCUSSION}

Using the data presented, it is now possible to scientifically deduce suitable dimensions for a feeding place for goats. Bearing in mind the individual circumstances of the farm, the feeding area can be designed so that the animals can reach all of the feed in the manger or on the feed table with a relaxed body posture. We used polled or hornless goats for practical reasons, but our result should also be applicable for horned goats. Our 


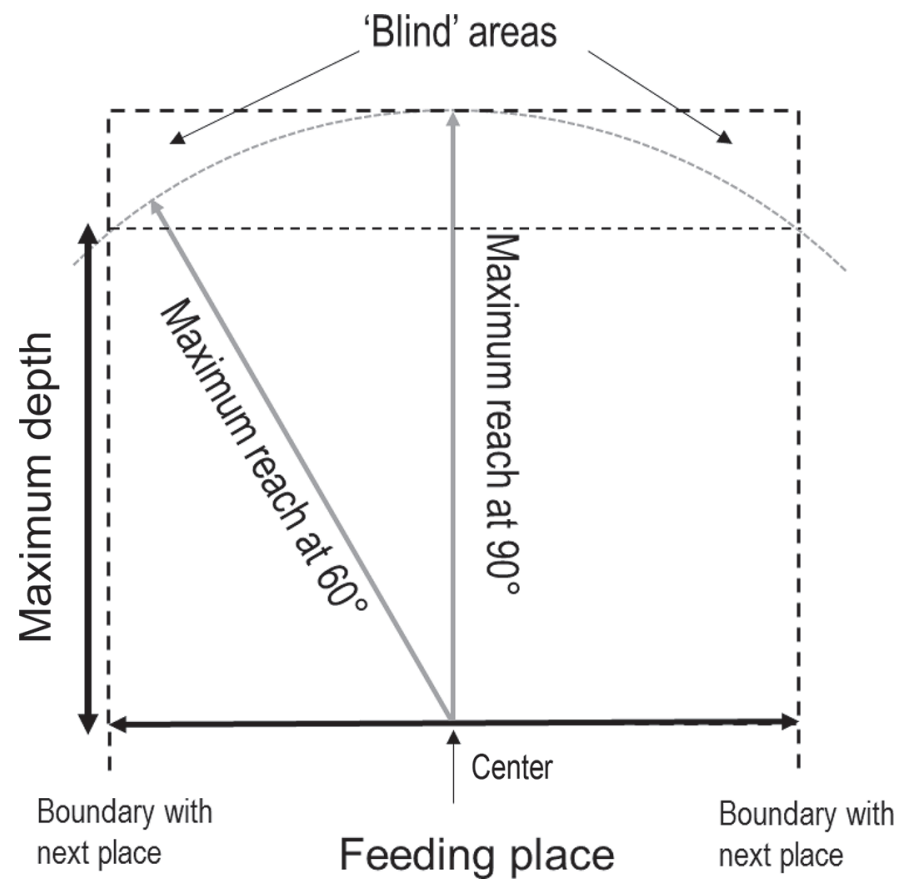

Figure 5. Schematic illustration for calculating the maximum depth of a feed table or manger using the maximum reach allowing goats to access all feed spread over the entire width of a feeding place, with the elimination of blind areas.

goats were healthy, lactating females of dairy breeds and sizes common in Europe. We assumed that reach would have been smaller if sick, lame, old, or heavily pregnant goats had been included in the study. Other breeds, such as meat or dwarf goats, might have considerably different body dimensions, which would limit the applicability of our results to these breeds as well. Feeding reach could also depend on the ration; for example, the reach for hay might increase along with fiber length. Furthermore, we tested goats individually and, thus, did not consider the influence of social interactions on reach. Nevertheless, we think that appropriate feed barrier dimensions can only serve to minimize the risk of injuries during social interactions. They cannot, however, prevent the occurrence of agonistic interactions caused by an insufficient number of feeding places (Loretz et al., 2004; Jørgensen et al., 2007), inadequate feeding management (e.g., roughage type: Jørgensen et al., 2007), or unfavorable type of barrier (Nordmann et al., 2013).

A feeding area step height of up to $20 \mathrm{~cm}$ appears to have no influence on the reach of the goats when feeding. Larger step heights than this, however, produce a stronger flexion of the back, which at some stage is likely to cause a decrease in reach. Further studies are needed to clarify the matter, as feeding area step heights of over $20 \mathrm{~cm}$, which require less-frequent mucking-out of the deep litter, are quite common in practice. Investigating whether a feeding area step puts excessive stress on the goats' joints or hooves by causing a nonphysiological change in posture would be another useful avenue of inquiry.

The minimum reach of the goats was independent of the height of the feed table, but was influenced by their height at withers and feeding angle. Larger goats presumably have correspondingly longer necks, which makes reaching the feed near them easier. If the neck needs to be angled, it is plausible that the minimum reach decreases. However, it follows from the data that feed lying very close to the goats (i.e., up to a distance of approximately $15 \mathrm{~cm}$ ) cannot be reached easily. This is important when dimensioning the partition between pen and feed table, as this partition should have a certain depth or be wider at the base.

In accordance with the results obtained by Muhikambele et al. (1998), maximum reach increases along with increasing height at withers and height of the feed table. Our results allowed us to calculate the maximum possible manger depth or feed table depth. This is smaller than the maximum reach, so that the goats can also reach the feed at the side over the entire width of the feeding place available to them. If too great a manger or feed table depth is chosen for a one-sided feed table, danger exists that animals will brace themselves against the feeding barrier to reach the feed, that too much feed will go uneaten, or that the feed will have to be topped off too often. With feed tables used on both sides, generally equipped with feed belts or (elevated) conveyor systems, it is also important to dimension the depth correctly so that goats standing opposite one another do not get in each other's way but are still also able to consume the feed in the center of the table.

In cattle husbandry, the feed table is commonly raised by 15 to $20 \mathrm{~cm}$ above the standing level (Fernández et al., 2006; Huzzey et al., 2006). This compensates for the fact that the animals at the feeding barrier cannot feed as they would on pasture (i.e., they cannot splay their legs, a posture which allows them to reach the ground easily with their muzzle). Consequently, some authors also suggest such a height difference for goats (Peacock, 1996; Muhikambele et al., 1998; Upreti et al., 2005). Our data demonstrate that the minimum height difference between standing surface of forelegs and feed table should not be less than $10 \mathrm{~cm}$. With a smaller difference, the animals had difficulties feeding in a relaxed posture, and the weight load on the front limbs here could also lead to health problems in goats. In a study with cattle, Boxberger (1983) showed that the average load on the forelegs of 64 to $68 \%$ of $\mathrm{BW}$ at 
a feed table height of $0 \mathrm{~cm}$ falls to 57 to $63 \%$ of $\mathrm{BW}$ at a feed table height of $10 \mathrm{~cm}$. Presumably, a long-lasting nonphysiological shift in weight load to the front limbs poses a risk for hoof and joint health. We may also assume that it increases the pressure of the body on the feed barrier rails, which can cause skin lesions (Kielland et al., 2010).

Manger or feed table loading capacity is determined by height of partition between pen and feed table, feed table height, and feed table depth (see Figure 2, dimensions $\mathrm{A}, \mathrm{B}, \mathrm{C}$ ). As the goats increase in reach is less than a given increase in feed table height, a low feed table height (but no lower than $10 \mathrm{~cm}$ ) is recommended as yielding the highest possible feed table-loading capacity. A high capacity should be the aim, as it requires less-frequent topping off and readily ensures the ad libitum availability of feed to the goats. For a high loading capacity, as high a partition as possible between pen and feed table should be chosen. This partition is part of any feed bunk system and separates the animals from the feed. If this partition is not adjusted to the smallest animal of the herd, however, at least some of the animals will need to rest their necks on the edge of the partition when feeding, possibly resulting in bruising or hematomas. For goats, therefore, a partition of optimum height should be adjusted to approximately the height of the point of the shoulder and to below the base of the neck of the animal. Although this is higher than the top of the metacarpus (Kielland et al., 2010), goats, unlike cattle, do not have a dewlap that must be taken into account when determining recommendations. In the present experiment, guide values of 35 and $55 \mathrm{~cm}$ should be helpful when setting the partition height for goats with a height at withers of 60 and 80 $\mathrm{cm}$, respectively. Furthermore, in our study the neck rail was set as deep as possible for the individual goat, but at least $30 \mathrm{~cm}$ above withers height to prevent the goat from being able to leave the stall via the feeding barrier and to give unrestricted freedom of movement as it fed. Although we cannot conclude the optimal height of the neck rail from this specification, it could be helpful when designing feeding barriers for goats.

As far as animal size is concerned, the model estimates showed that animals with a $20-\mathrm{cm}$ difference in height at withers differed relatively little in terms of both maximum (approximately $5 \mathrm{~cm}$ ) and minimum (approximately $8 \mathrm{~cm}$ ) reach while feeding. For both of the investigated outcome variables, the next-mostprobable model had a very similar Bayesian information criterion and no longer contained the effect of height at withers; this also shows that the influence of body size in the reach measured by us should not be overestimated. Nevertheless, using the dimensions of the smallest animals of the herd as a guide when deciding on feed table height as well as manger and feed table depth will ensure that all of the animals will be able to reach the feed comfortably. Only in the case of a feed table used on both sides - usually with feed belts or (elevated) conveyor systems - could this approach lead to problems, with considerably larger animals standing opposite one another potentially getting in each other's way.

In summary, the results of the present study are useful for defining suitable dimensions for dairy goat feeding places to ensure that the animals are able to reach all of the feed in the manger or on the feed table with a relaxed posture and to prevent injuries and stress to joints and hooves. Although a feeding area step of up to a maximum of $20 \mathrm{~cm}$ need not be taken into account with respect to feeding reach, raising the feed table at least $10 \mathrm{~cm}$ above the standing area of the forelegs is essential to allow the goats to feed in a species-appropriate manner.

\section{ACKNOWLEDGMENTS}

Our special thanks go to the owner of the goats for providing the animals for the experiment, and to HansRuedi Ott (Agroscope, Tanikon, Ettenhausen, Switzerland) for constructing the feeding stall. This project was financed by the Federal Food Safety and Veterinary Office (Bern, Switzerland; Project No. 2.09.04).

\section{REFERENCES}

Abijaoudé, J. A., P. Morand-Fehr, J. Tessier, Ph. Schmidely, and D. Sauvant. 2000. Diet effect on the daily feeding behaviour, frequency and characteristics of meals in dairy goats. Livest. Prod. Sci. 64:29-37.

Andersen, I. L., and K. E. Boe. 2007. Resting pattern and social interactions in goats - The impact of size and organisation of lying space. Appl. Anim. Behav. Sci. 108:89-103.

Aschwanden, J., L. Gygax, B. Wechsler, and N. M. Keil. 2008. Social distances of goats at the feeding rack: Influence of the quality of social bonds, rank differences, grouping age and presence of horns. Appl. Anim. Behav. Sci. 114:116-131.

Barroso, F. G., C. L. Alados, and J. Boza. 2000. Social hierarchy in the domestic goat: Effect on food habits and production. Appl. Anim. Behav. Sci. 69:35-53.

Barton, B. 2012. MuMIn: multi-model inference. Accessed Feb. 10, 2012. http://CRAN.R-project.org/package=MuMIn.

Boxberger, J. 1983. Wichtige Verhaltensparameter von Kühen als Grundlage zur Verbesserung der Stalleinrichtung. Postdoctoral thesis. Faculty of Agricultural and Horticultural Sciences, TU Munich, Weihenstephan, Germany.

Dumelow, J. 1987. Development of a new design of cattle feeding barrier. Farm Buildings and Engineering 4:25-27.

Fernández, M. E., R. A. Marino, and X. C. Carreira. 2006. Algorithms for dairy barn design: Resting, feeding, and exercise. J. Dairy Sci. 89:2784-2798.

Ferreira, L. M. M., R. Celaya, R. Benavides, B. M. Jáuregui, U. García, A. S. Santos, R. R. García, M. A. M. Rodrigues, and K. Osoro. 2013. Foraging behaviour of domestic herbivore species grazing on 
heathlands associated with improved pasture areas. Livest. Sci. 155:373-383.

Huzzey, J. M., T. J. DeVries, P. Valois, and M. A. G. von Keyserlingk. 2006. Stocking density and feed barrier design affect the feeding and social behavior of dairy cattle. J. Dairy Sci. 89:126-133.

Jørgensen, G. H. M., I. L. Andersen, and K. E. Bøe. 2007. Feed intake and social interactions in dairy goats - The effects of feeding space and type of roughage. Appl. Anim. Behav. Sci. 107:239-251.

Kielland, C., K. E. Bøe, A. J. Zanella, and O. Østerås. 2010. Risk factors for skin lesions on the necks of Norwegian dairy cows. J. Dairy Sci. 93:3979-3989.

Loretz, C., B. Wechsler, R. Hauser, and P. Rüsch. 2004. A comparison of space requirements of horned and hornless goats at the feed barrier and in the lying area. Appl. Anim. Behav. Sci. 87:275-283.

Muhikambele, V. R. M., E. Owen, J. E. Owen, and L. A. Mtenga. 1998. Capacity of goats to reach food through tombstone barriers, as affected by position of food, body weight and body dimensions. Anim. Sci. 66:415-422.

Nordmann, E., N. M. Keil, C. Schmied-Wagner, C. Graml, J. Langbein, J. Aschwanden, J. von Hof, K. Maschat, R. Palme, and S.
Waiblinger. 2013. Feed barrier design affects behaviour and physiology in goats. Appl. Anim. Behav. Sci. 133:40-53.

Peacock, C. 1996. Improving Goat Production in the Tropics: A Manual for Development Workers. Oxfam, Oxford, UK.

Pinheiro, J., D. Bates, S. Debroy, D. Sarkar, and R Development Core Team. 2012. nlme: Linear and Nonlinear Mixed Effects Models. R package Version 3.1-105. www.r-project.org.

R Core Team. 2015. R: A language and environment for statistical computing, R Foundation for Statistical Computing, Vienna, Austria.

Toussaint, G. 1997. The housing of milking goats. Livest. Prod. Sci. 49:151-164.

Upreti, C. R., B. S. Kuwar, and S. B. Panday. 2005. Development and evaluation of improved feeders for goats suitable to stall-fed management system. Nepal Agric. Res. J. 6:78-83.

Yu, Y., and L. Lin. 2012. Agreement: Statistical Tools for Measuring Agreement. R package version 0.8-1. www.r-project.org. 